\title{
Impedance Investigation of Milk Dilution
}

\author{
Amine Abdelkafi, Paul Büschel, Ahmed Fendri, Olfa Kanoun \\ Chair of Measurement and Sensor Technology \\ Technische Universität Chemnitz, Germany \\ Reichenhainer Straße 70, 09126 Chemnitz, Germany \\ Amine.abdelkafi@s2013.tu-chemnitz.de
}

\begin{abstract}
To ovoid different kind of milk adulteration is it important to control parameters like fat and water content because of their influence on its nutritional value. Therefore it is desired to have a simple way of measuring these values during the processing of milk. In this study, where made that vary water content and temperature to investigate whether or not impedance spectroscopy can be a tool to access milk adulteration. The performance of the sensor is tested for milk adulterated with deionized water in the frequency range $40 \mathrm{~Hz}$ to $110 \mathrm{MHz}$ at different temperature between $6^{\circ}$ and $40^{\circ} \mathrm{C}$; it has been observed that the sensor can identify $5 \%$ of water adulteration, at high and medium frequencies. Results indicate that it is possible to discriminate between milk that was diluted with water. It exhibits also; changes in temperature of milk exert a significant effect on changes in its conductance and capacitance properties. Thus impedance can be a tool to construct process monitoring sensor for milk processing.
\end{abstract}

Key words: Impedance spectroscopy, sensor, milk, adulteration

\section{Introduction}

Safety of food is an undeniable priority to ensure a good quality of different foods. Byproducts and other ingredients from unknown sources may be added to essential foods of the consumer's daily life [1-2], threatening their health and metabolism [3]. These fraudulent practices are reproduced in various food industries, especially in the dairy industry [4]. In this study, milk adulteration was investigated. The principal constituents of milk are water, lipids including phospholipids, cholesterol and free fatty acids; lactose or milk sugar which is the distinctive carbohydrate of milk and proteins (about four fifths of the protein consists of casein) [5-6], moreover, milk contains numerous minor proteins, including a wide range of enzymes. Furthermore, milk has many miscellaneous components, often in trace amounts. The total content of all substances except water is called the content of dry matter. This rich milk composition shows the importance of the nutritional value of this white liquid which is necessary in the daily life of humans and the growth of children. For this reason, any alteration of milk, can cause loss of its quality and also can threaten the health of the consumer. The simplest way of fraud is addition of water to increase its volume for greater benefits [7]. Adding water is strongly influences a loss in milk quality and is a risk to consumers' safety. Several methods were cited to detect water content in milk such as freezing point osmometry method [8], which is costly. Electrical measurement data over a wide range of frequencies have been used to provide fundamental information about the electrical conduction behaviour of milk and other dairy products [9-10], such as electrochemical Impedance Spectroscopy (EIS) which is a powerful technique can be used to characterize liquids by measuring the impedance as a function of frequency. EIS studies the system response of an electrochemical system to the application of a periodic small amplitude alternative current (AC) signal. The input and the resulting output are further processed to response to yield useful information about the physicochemical properties of the system.

In this study, we apply impedance spectroscopy to investigate added water content and temperature effect in milk obtained from local markets by varying the frequencies and temperatures. 


\section{Experimental procedure}

\section{Measurement setup}

Impedance measurements, in the frequency range of $40 \mathrm{~Hz}$ to $110 \mathrm{MHz}$, were performed using Agilent 4294A impedance analyser. A two terminal configuration was used to connect the device electrodes to the impedance analyser. The sensing devices consisted of two platinum electrodes. The amplitude of the $A C$ voltage was $10 \mathrm{mV}$. The conductivity of milk as a function of water content was determined using samples obtained from local supermarkets. The fat content in the full fat milk is $3.5 \%$. Five milk samples of $100 \mathrm{ml}$ were prepared from an initial concentration of $3.5 \%$ fat (M1) under same environmental condition then kept in climate chamber at constant temperature of $2^{\circ} \mathrm{C}$ to inhibit especially growth of microorganisms and enzyme action. The samples M2 to M5 were diluted by adding deionized water (Table 1). The sensor is dipped inside the test medium to measure the impedance of milk at 5 different temperatures $\left[6,14,22,30\right.$ and $40{ }^{\circ} \mathrm{C}$. The conductivity measuring cell is directly connected to the Agilent 4294A impedance measuring device, so parasitic factors can be avoided (Figure 1). Before each experiment, the sensor was washed in ethanol, rinsed with deionized water. Each experiment is repeated two times to check the reproducibility.

Table 1 Samples prepared for measurements

\begin{tabular}{|c|c|c|c|c|c|}
\hline $\begin{array}{c}\text { Milk } \\
\text { Fat \% }\end{array}$ & $\begin{array}{c}\text { M1 } \\
(3.5)\end{array}$ & $\begin{array}{c}\text { M2 } \\
(3)\end{array}$ & $\begin{array}{c}\text { M3 } \\
(2.5)\end{array}$ & M4(2) & M5(1.5) \\
\hline $\begin{array}{c}\text { Water } \\
(\%)\end{array}$ & 0 & 5 & 10 & 15 & 20 \\
\hline $\begin{array}{c}\text { Milk } \\
(\%)\end{array}$ & 100 & 95 & 90 & 85 & 80 \\
\hline
\end{tabular}

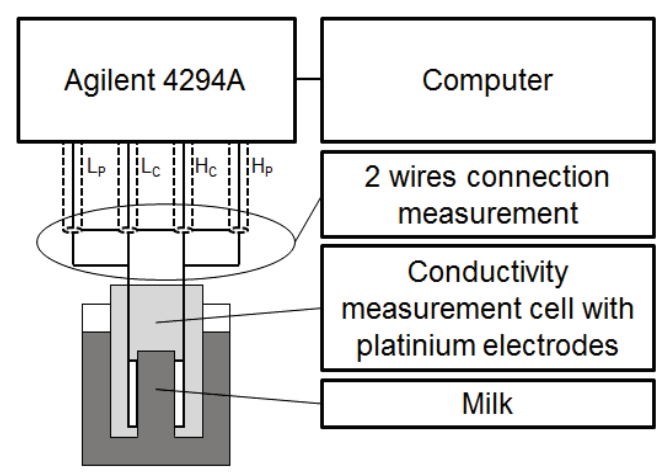

Figure 1 Measurement setup

\section{Result and Discussion}

\section{Temperature Effect}

Impedance spectra reveal a capacitive arc at high and intermediate frequencies with different diameter depending on the temperature while the diffusion effect is at low frequencies. Inductive effect is absent in these curves (Figure 2). At low frequency a remarkable decrease of impedance value when temperature is increasing from $6^{\circ} \mathrm{C}$ to $40^{\circ} \mathrm{C}$ were shown ( $\sim 45 \%$ decreasing). Milk is a dilute aqueous solution with a specific conductivity of $4 \ldots 5 \mathrm{mS} / \mathrm{cm}$ (at around $1 \%$ fat content) [11] mostly caused by mineral substances, primarily potassium $\left(\mathrm{K}^{+}\right)$, sodium $\left(\mathrm{Na}^{+}\right)$, calcium $\left(\mathrm{Ca}^{2+}\right)$ and chlorides $\left(\mathrm{Cl}^{-}\right)$ions. The dielectric constant is almost as high as that of pure water, polar substances dissolve well in milk and salts tend to dissociate. For these reasons an increase milk temperature a decrease in its viscosity and an increase in the mobility of the ions in solution. Also it may cause an increase in the number of ions in solution due to dissociation of molecules. As the electrolyte conductivity depends on the mentioned factors, an increase of milk temperature will lead to an increase in its conductivity.

The variation of the capacitance electrode depends on the electrode geometry and the electrolyte in between the electrode surfaces. The temperature of the measured liquid has a big influence on the measurements results, as the physicochemical properties of solution depend on it.

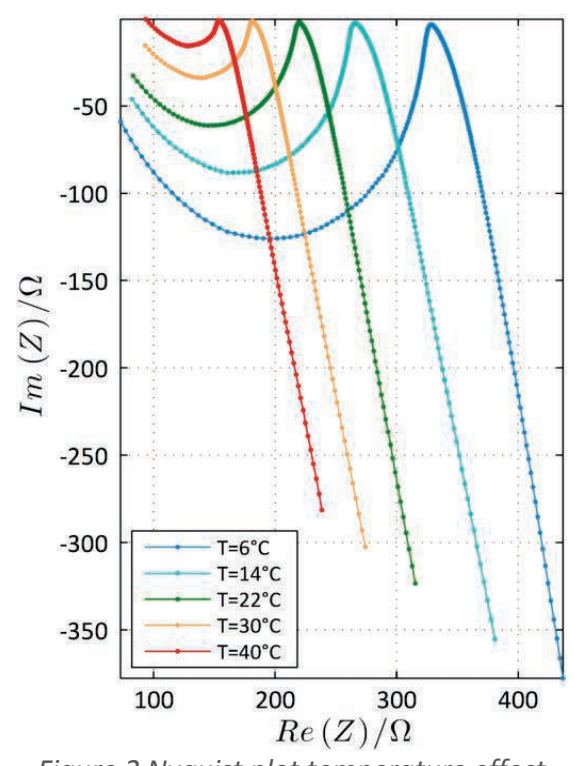

Figure 2 Nyquist plot temperature effect 


\section{Water Addition Effect}

Milk density equals about $1029 \mathrm{~kg} \cdot \mathrm{m}^{-3}$ at $20^{\circ} \mathrm{C}$; it varies especially with fat content, and its viscosity is low, about twice that of water, which means that milk can readily be mixed, even by convection currents resulting from small temperature fluctuations [12]. Nyquist diagram is plotted in Figure 3 with respect to the addition of different percentage of deionized water. It is observed that the impedance increases with the addition of water.

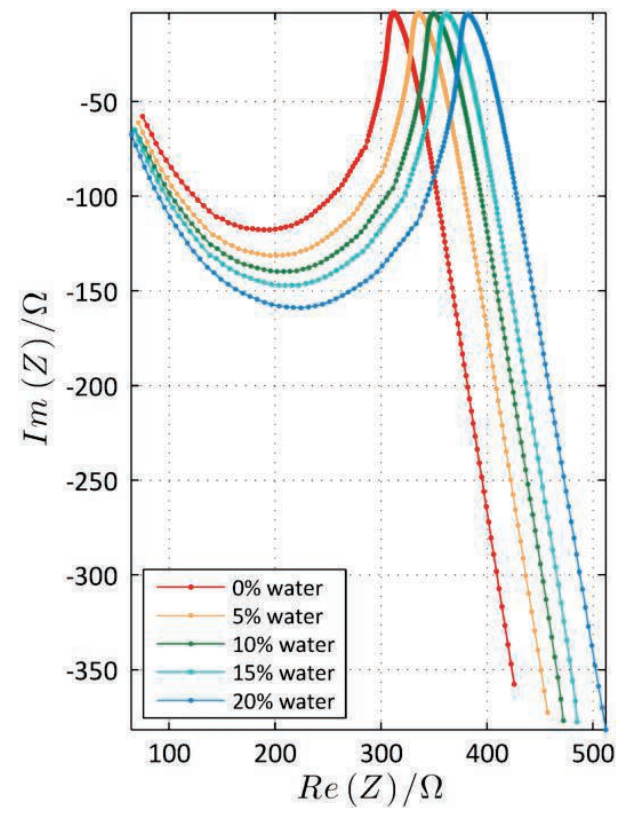

Figure 3 Nyquist plot water content

Compared to deionized water, which has a conductivity of $\approx 50 \mathrm{nS} / \mathrm{cm}$ (tap water 0.5 $\mathrm{mS} / \mathrm{cm}$ ) milk has 4 to $5 \mathrm{mS} / \mathrm{cm}$ which is at least a factor 10 more. The change of conductivity is in the range of $-0.0388 \mathrm{mS} / \mathrm{cm} \%$ (per \% water added to milk) [13]. This indicates that the detection of water diluted milk should be possible. This is also indicated in Figure 3 where the dependence of the impedance on the dilution is visible at high and medium frequencies. It should be mentioned that milk contains almost $80 \%$ of water and addition of small amount of water is difficult to sense, it is also heavily influences by colloidal Calcium phosphate complexes which thus it cannot serve as tool for the detection of dilution of milk by water [14]. The platinum electrode can only be able to detect when minimum of $5 \%$ water is added and gives $6.5 \%$ change in the impedance value at high frequency. Though the aim of this study is to identify adulterated milk by water, the sensor can detect impedance variation only in high and medium frequencies. The added water from $5 \%$ to $10 \%, 10 \%$ to $15 \%$ and $15 \%$ to $20 \%$ impedance value increases less than $5 \%$ and from $5 \%$ to $20 \%$ about the increase of impedance is about $18 \%$. Milk adulteration by water requires precise instrumentation system for a good detection. Milk is acidic solution with a $\mathrm{pH}$ value about 6.7 at room temperature. Addition of water tries to shift it towards neutral solution. As the $\mathrm{pH}$ value changes from acidic nature toward basic solution, conductivity decreases. So the nature of change of impedance is same like that of change of conductivity.

\section{Equivalent Circuit}

The most common method used to analyze EIS spectra is the equivalent circuit modeling. The behavior of each element is then described in terms of "classical" electrical components (resistors, capacitors, inductors) plus a few specialized electrochemical elements (such as Warbug diffusion elements) [15].

The electrical impedance between tow electrodes immersed in an electrolyte can be modelled using series and parallel combinations of capacitors and resistors. An insight into the equivalent circuit can be obtained by plotting the imaginary part of the complex impedance against its real component. The complex impedance for the different milk samples as a function of frequency are shown in Figure 4.

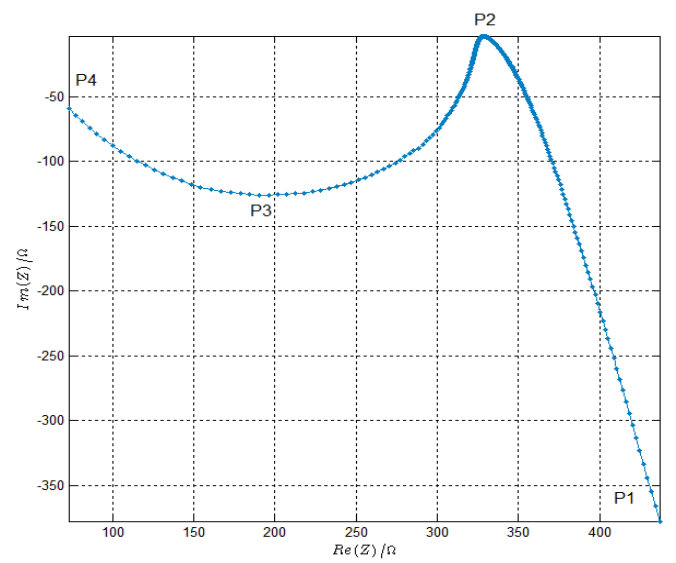

Figure 4 Impedance spectra for $M 13.5 \%$ fat $T=6^{\circ} \mathrm{C}$

Table 2 Definition of characteristic points in the impedance spectrum

\begin{tabular}{|c|l|}
\hline Name & \multicolumn{1}{|c|}{ Definition } \\
\hline P1 & $\begin{array}{l}\text { Smallest measured frequency } \\
40 \mathrm{~Hz}\end{array}$ \\
\hline P2 & $\begin{array}{l}\text { Maximum imaginary part of the } \\
\text { impedance at low frequencies }\end{array}$ \\
\hline P3 & $\begin{array}{l}\text { Minimum imaginary part at high } \\
\text { frequencies }\end{array}$ \\
\hline P4 & $\begin{array}{l}\text { The largest measured frequency } \\
110 \mathrm{MHz}\end{array}$ \\
\hline
\end{tabular}


Characteristic points occur in almost all measured impedance spectra. Their situation describes an impedance spectrum almost completely and summarizes the information contained therein in the fewest possible number of values together (Table 2). For modelling the impedance spectrum, the equivalent circuit is shown in Figure 4. It maps the mechanisms of the conductivity cell. The resistance R1 summarizes all serial resistances of the measurement setup and more at very high frequency in the range of the characteristic point. The resistor R2 describes the electrolytic conductivity of the milk. The element C1 summarizes the capacitive properties of the cell together. Electrolytic conductivity and capacitive properties of the cell function primarily in the range of the characteristic points $P 2$ and $P 3$. $\mathrm{CPE}$ represents the remaining diffusion effects at the electrode and in the part of the characteristic points P1 and P2. The impedance spectra can be evaluated by software according to these parameters.

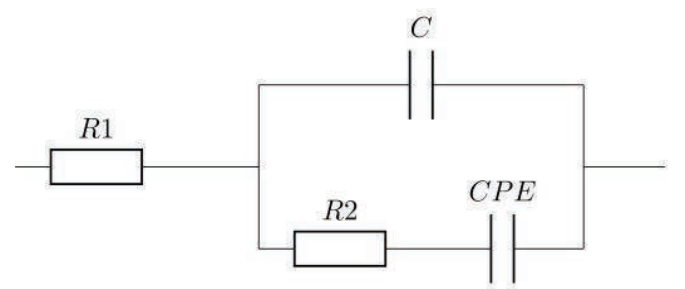

Figure 5 Equivalent circuit

\section{Conclusion}

Impedance spectroscopy has revealed a systematic relationship between water content and the impedance spectrum. It exhibits a rapid variation at low and medium frequencies, but remains constant at high frequencies. The advantage of using impedance spectroscopy is that it is a low cost method; immediate obtaining of spectra and also it is a nondestructive method to control the milk quality. The investigations carried out show important correlations between impedance spectra measured at different temperature with varying water content. Further work will focus on the study of aging effect to obtain a more detailed analysis of milk freshness.

\section{References}

[1] Moore, J. C., Spink, J., \& Lipp, M. (2012). Development and application of a database of food ingredient fraud and economically motivated adulteration from 1980 to 2010. Journal of Food Science, 77(4), R118R126.
[2] Santos, P. M., Pereira-Filho, E. R., \& Rodriguez-Saona, L. E. (2013). Rapid detection and quantification of milk adulteration using infrared microspectroscopy and chemometrics analysis. Food chemistry, 138(1), 19-24.

[3] Aquino, L. F. M. C., Silva, A. C. O., Freitas, M. Q., Felicio, T. L., Cruz, A. G., \& ConteJunior, C. A. (2014). Identifying cheese whey an adulterant in milk: Limited contribution of a sensometric approach. Food Research International, 62, 233-237.

[4] M.D. Jenkins, J.M. Delwiche, Manometric biosensor for on-line measuremen of milk urea, Biosensors and Bioelectronics 17 (2002) 557-563.

[5] Thompson, Abby, M.Boland, and H.Singh, eds. Milk proteins: from expression to food. Academic Press, 2009.

[6] Park, Y. W., et al. "Physico-chemical characteristics of goat and sheep milk." Small Ruminant Research 68.1 (2007): 88113.

[7] A.A.H. Adam, Milk adulteration by adding water and starch at Khartoum state, Pakistan Journal of Nutrition $8 \quad$ (4) (2009) 439440.

[8] Büttel, B., Fuchs, M., \& Holz, B. (2008). Freezing point osmometry of milk to determine the additional water content-an issue in general quality control and German food regulation. Chemistry Central Journal, 2(1), 6.

[9] N. Therdthai, W. Zhou, Artificial neural network modelling of the electrical conductivity property of recombined milk, J. Food Eng. 50 (2001) 107111.

[10] B.A. Lawton, R. Pethig, Determining the fat content of milk and cream using $A C$ conductivity measurements, Meas. Sci. Technol. 4 (1993) 38-41.

[11] Lawton, B. A., and R. Pethig. "Determining the fat content of milk and cream using $A C$ conductivity measurements." Measurement Science and Technology 4.1 (1993): 38.

[12] Walstra, P., Walstra, P., Wouters, J. T., \& Geurts, T. J. (2014). Dairy science and technology. CRC press.

[13]M. F. Mabrook and M. C. Petty, "Application of electrical admittance measurements to the quality control of milk," Sensors Actuators B Chem., vol. 84, no. 2-3, pp. 136-141, May 2002.

[14] P. F. Fox and P. L. H. McSweeney, "Dairy Chemistry and Biochemistry," Springer, 1998.

[15] Macdonald, J. R., \& Barsoukov, E. (2005). Impedance spectroscopy: theory, experiment, and applications. History, 1, 8. 